\title{
Light Intensity Affects the Coloration and Structure of Chimeric Leaves of Ananas comosus var. bracteatus
}

\author{
Wei Yang, Yuke Lin, Yanbin Xue, Meiqin Mao, Xuzixing Zhou, Hao Hu, Jiawen Liu, Lijun Feng, \\ Huiling Zhang, Jiaheng Luo and Jun Ma
}

College of Landscape Architecture, Sichuan Agricultural University, Chengdu, 611130, China

*Corresponding Author: Jun Ma. Email: junma365@hotmail.com

Received: 02 April 2021 Accepted: 29 June 2021

\begin{abstract}
Ananas comosus var. bracteatus is an important ornamental plant because of its green/white chimeric leaves. The accumulation of anthocyanin makes the leaf turn to red especially in the marginal part. However, the red fades away in summer and winter. Light intensity is one of the most important factors affecting leaf color along the seasons. In order to understand the effects of light intensity on the growth and coloration of the chimeric leaves, Ananas comosus var. bracteatus was grown under full sunlight, 50\% shade and $75 \%$ shade for 75 days to evaluate the concentration of pigments, the color parameters (values $\mathrm{L}^{*}, \mathrm{a}^{*}, \mathrm{~b}^{*}$ ) and the morpho-anatomical variations of chimeric leaves. The results showed that a high irradiance was beneficial to keep the chimeric leaves red. However, prolonged exposure to high irradiance caused a damage, some of the leaves wrinkled and even burned. Shading instead decreased the concentration of anthocyanin and increased the concentration of chlorophyll, especially in the white marginal part of the leaves. Numerous chloroplasts were observed in the mesophyll cells of the white marginal part of the chimeric leaves under shading for 75 days. The increase in chlorophyll concentration resulted in a better growth of plants. In order to balance the growth and coloration of the leaves, approximately $50 \%$ shade is suggested to be the optimum light irradiance condition for Ananas comosus var. bracteatus in summer.
\end{abstract}

\section{KEYWORDS}

Ananas comosus var. bracteatus; light intensity; leaf color; anatomy

\section{Introduction}

Variegated leaf chimeric plants are important ornamental plants because of their unique colorful characteristics. The high diversity of color in chimeric plants is due to the changes of spatial distribution of pigment types, concentrations and proportions in the leaves. These changes are the result of the interaction between genetic and environmental factors [1-3]. Climate, soil nutrients, and water have long been understood to be primary factors influencing plant growth, and the light intensity is an important environmental factor [4,5]. In green leaves, chlorophyll dominates in pigments causing a green appearance, and chlorophyll deficiency can make leaves become white or yellow. Light intensity can affect the concentration of chlorophyll, carotenoid, and anthocyanin in the leaves, leading to variation in leaf color [6]. It has been shown that different plants have different acclimation potential to light intensity. Photinia $\times$ fiaseri grown under full light was more densely foliated than shaded plants [7]. 
Approximately $67 \%$ of natural light (the irradiance intensity of sunlight was about $2500 \mu \mathrm{mol} \mathrm{m} \mathrm{s}^{-1}$ at noon during September in Jinhua) was concluded to be the optimum light irradiance conditions for Tetrastigma hemsleyanum Diels et Gilg [4]. The research conducted by Kong et al. [8] showed that $30 \%$ and $50 \%$ of sunlight (the irradiance intensity of sunlight was about $2000 \pm 20 \mu \mathrm{mol}$ photons $\mathrm{m}^{-2} \mathrm{~s}^{-1}$ at noon) were the most suitable growth environment for Mahonia bodinieri (Gagnep.) Laferr, obtaining higher biomass and improving the plant economic value. In addition, light intensity can tightly regulate color changes. Galax urceolata leaves had a transition from red to green along with the decrease of light intensity [9]; Kalamegh leaf changed its color from green to red from time to time under varying intensities of light and shade [10]. Similarly, shading was reported to improve foliar color of Kalmia latifolia L from yellow-green to dark green in the first year of production [11]. The leaves of both 'Royal Glissade' and 'UF06-1-6' gradually changed from green to red under different light environments, the anthocyanin concentration increased while chlorophyll concentration decreased [12]. A study in Arabidopsis thaliana shown that light intensity can affect the type of anthocyanin [13]. Anthocyanins accumulate in the form of glycosides in plant vacuoles. In plants, they can provide colorations in flowers, fruits, stems, and leaves of plants ranging in color from red to purple. Sugars are structural components, energy sources and signals regulating the expression of various genes in the primary and secondary metabolisms. Some studies showed that sugar concentration is one of the factors affecting anthocyanin synthesis. For example, sugars promoted the accumulation of anthocyanins in radish hypocotyls and grape berries [14,15], and the anthocyanin synthesis was enhanced by exogenous sugar in several plant species. Furthermore, the balance of biosynthesis and degradation determines the anthocyanin concentration. The anthocyanin biosynthetic pathway has been extensively studied in many plants. Phenylalanine ammonia lyase (PAL), chalcone synthase $(\mathrm{CHS})$, chalcone isomerase $(\mathrm{CHI})$, flavanone 3-hydroxylase $(\mathrm{F} 3 \mathrm{H})$, dihydroflavonol 4-reductase (DFR), and anthocyanidin synthase (ANS) are the main enzymes in this pathway [16]. Anthocyanin concentration was also reported to be related to the polyphenol oxidase (POD) and peroxidase (PPO) activities. However, the mechanism of its degradation is complicated and there are only few studies about it $[17,18]$.

Plants develop specific changes to acclimate to different light conditions for their survival, these changes in morphology, physiology, structure of leaves and chloroplasts can be adaptable [19,20]. For instance, the changes in anatomical structure can maximize photosynthetic efficiency and keep internal temperatures at optimal levels [21,22]. Ultrastructure of chloroplasts in plants change significantly with increased irradiance, and the number of chloroplasts under high light is lower than under low light. Moreover, plants grown under high irradiance can use the energy of many photons and maintain a high photosynthetic net rate, but chronic photo-inhibition may occur upon a too long prolonged exposure to high light conditions. Therefore, it is very important to investigate the characteristics of leaf morphology and anatomy of plants under different light conditions for the cultivation of Ananas comosus var. bracteatus.

Ananas comosus var. bracteatus, belonging to the family Bromeliaceae, is a herbaceous perennial monocot. It has a high ornamental value all year round due to its green/white chimeric leaves. During spring and autumn, the leaves are bright red, which improves a lot the ornamental value of $A$. comosus var. bracteatus [23]. However, in summer and winter, the redness of the leaves gradually fades, and the leaf becomes green/white. How to maintain the red coloration of leaves is an important way to improve the ornamental and economic value of $A$. comosus var. bracteatus. Therefore, we have carried out a lot of studies on the molecular mechanism of chimera traits formation of on this species [24-28]. Recently, we conducted a study on pigments metabolome in the leaves of A. comosus var. bracteatus [29]. When the leaf turned red, the chlorophyll concentration in the green central part could reach 57 times higher than that in the red marginal part, while the anthocyanins accounted for $93.2 \%$ of all pigments in red marginal part with a small proportion of chlorophyll and carotenoid. According to the results, we determined that anthocyanin and cyanidin derivatives presenting different degrees of red color, accounted for $97 \%$ of total 
anthocyanin concentration. Cyanidin-3,5-O-diglucoside, accounting for $98 \%$ of cyanidin derivatives in red marginal part, was the most important anthocyanin for the red phenotype. The genetic characteristics and physiological properties of other variegated leaf chimeric plants have been systematically studied [3033]. However, few studies have addressed how chimeric plants respond to varying light intensity, and the mechanism under it is still unknown.

The objective of our study was to determine the optimum light intensity for the growth and high ornamental value of $A$. comosus var. bracteatus by investigating the effects of different light intensities on the coloration change, pigments concentration and proportion, and internal anatomy of chimeric leaves. Our findings would provide a reference for the production application of $A$. comosus var. bracteatus, and be beneficial to the nursery and landscape industries.

\section{Materials and Methods}

\subsection{Plants Materials and Culture Condition}

Two-year-old Ananas comosus var. bracteatus plants with red chimeric leaves were collected from the experimental field at Sichuan Agricultural University, located in Chengdu, China. All of the samples were healthy and of the same age. The temperature is $18.4 \sim 32.3^{\circ} \mathrm{C}$ between June and September. The highest light intensity in daytime at noon is approximately $2500 \mu \mathrm{mol} \mathrm{m} \mathrm{m}^{-1}$ during the summer. Annual average rainfall is $957.05 \mathrm{~mm}$. Plants were grown in pots containing a mixture of coconut bran and river sand (1:2). Row spacing between plants was set $30 \mathrm{~cm} \times 30 \mathrm{~cm}$. Plants were divided into three treatments: natural sun-light condition (CK), 50\% shading condition (T1), and 75\% shading conditions (T2). Shading was accomplished by using one or two layers of commercial black cloth shade. Each treatment had 30 pots, there were a total of 90 pots for all three treatments. In order to ensure each individual received on average an equal irradiance under each treatment, the positions of pots were changed randomly every 15 days. The other conditions were uniform during the experimental period. We analyzed three independent biological replicates, and each replicate from three randomly selected plants. Each sample from the fourth or fifth leave of randomly selected plants was collected every 15 days from June 16 to September 01 in 2018. The middle parts of these leaves were divided into two types of samples based on the color: the green parts and the red parts (Fig. 1). The marginal parts from the same leaves were mixed up for weighing. After washing with distilled water, the samples were collected for further color parameters and pigments detection.
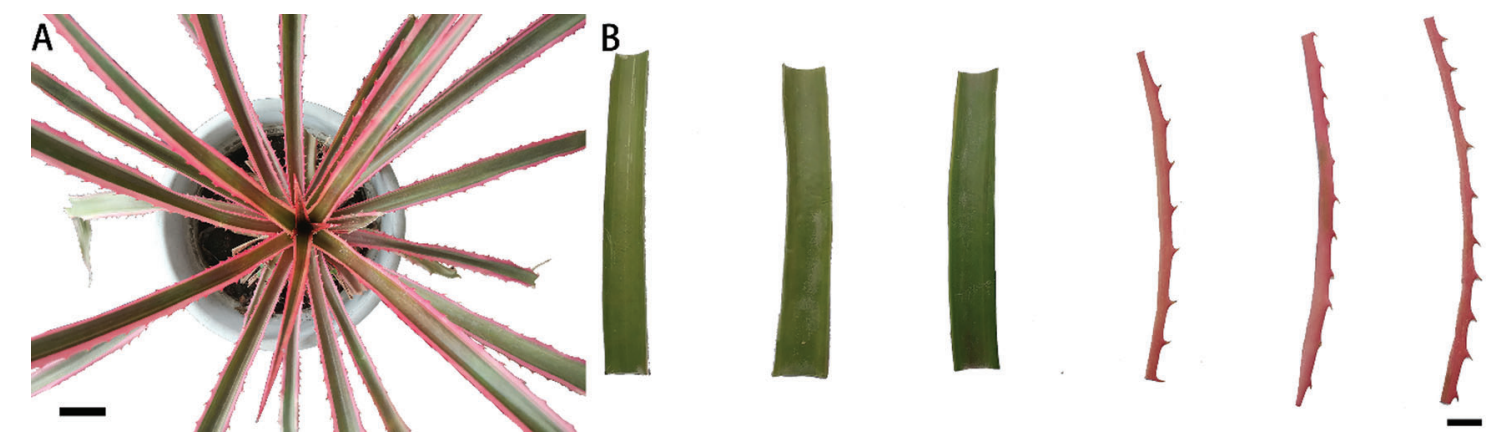

Figure 1: (A) Ananas comosus var. bracteatus chimeric plant, $\mathrm{Bar}=5 \mathrm{~cm}$. (B) Green central parts and red edges from the middle parts of chimeric leaves, $\mathrm{Bar}=1 \mathrm{~cm}$

\subsection{Leaf Color Parameters}

Color parameters - $\mathrm{L}^{*}$ (Lightness), $\mathrm{a}^{*}$ (Redness) and $\mathrm{b}^{*}$ (Yellowness) values of leaves were measured by an automatic color meter (Konica Minolta CM-2600d, Japan). The measurement was taken on the surface of 
middle typical parts of chimeric leaves, and both the red and green parts of each sample were analyzed for three times. The detection was based on the Commission Internationale de l'Éclairage (CIE D65/10 ${ }^{\circ}$ ) scale [34]. The CIE color system defines the range of color using a CIE brightness parameter $\left(\mathrm{L}^{*}\right)$ and CIE chromaticity coordinates $\left(\mathrm{a}^{*}\right.$ and $\left.\mathrm{b}^{*}\right)$. $\mathrm{L}^{*}$ values from 0 to 100 indicate that the color ranges from black to white. Values from $-a^{*}$ to $+a^{*}$ indicate the change from green to red in the leaf color. Positive values of $\mathrm{b}^{*}$ indicate more yellow, and negative values of $\mathrm{b}^{*}$ indicate more blue. With the data, the following formula was used to calculate the color index: $\mathrm{CI}=\left(1000 \times \mathrm{a}^{*}\right) \div\left(\mathrm{L}^{*} \times \mathrm{b}^{*}\right)$ [35].

\subsection{Pigments Concentration Detection}

Both the green central parts and red marginal parts of three fresh leaves were cut into pieces separately, and weighed. Leaf material corresponding to $0.1 \mathrm{~g}$ was then put into centrifuge tubes with $5 \mathrm{ml} 95 \%$ ethanol (v/v). Samples were kept in the dark at room temperature for $48 \mathrm{~h}$ until the leaf turned completely colorless; the centrifuge tube was shaken several times during the extraction period. We used $95 \%$ ethanol as blank, and measured the absorbances of samples at 649,665 , and $470 \mathrm{~nm}$ respectively based on three replicates by a UV spectrophotometer (UV1901 s/UV1901PCS, Shanghai Youke Instrument Co., Ltd., China). The pigment concentration was calculated using the following formulas [36]:

$$
\begin{aligned}
& \text { Chl } a=13.95 A_{665 \mathrm{~nm}}-6.88 A_{649 \mathrm{~nm}} \\
& \text { Chl } b=24.96 A_{649 \mathrm{~nm}}-7.32 A_{665 n m} \\
& C h l=(C h l a+C h l \quad b) \times V \div 1000 \mathrm{~W} \\
& \text { Car }=\left[\left(1000 A_{470}-2.05 C h l a-114.8 C h l b\right) / 245\right] \times \mathrm{V} \div 1000 \mathrm{~W}
\end{aligned}
$$

where $\mathrm{Chl}$ is the total concentration of chlorophyll, Car is total the concentration of carotenoid. $\mathrm{A}_{665 \mathrm{~nm}}$ $\mathrm{A}_{649 \mathrm{~nm}}$ and $\mathrm{A}_{470 \mathrm{~nm}}$ are the absorbance of the extracts at $665,649,470 \mathrm{~nm}$, respectively. $\mathrm{V}$ is the total volume of extract, $\mathrm{W}$ is the fresh weight.

Total anthocyanin concentrations of red and green samples were measured based on a $\mathrm{pH}$ differential method [30]. $0.1 \mathrm{~g}$ of frozen samples was immersed in $5 \mathrm{ml}$ of methanol acidified with $1 \% \mathrm{HCl}$, and kept in the dark with shaking for $4 \mathrm{~h}$. Then, it was centrifuged at $15,000 \times \mathrm{g}$ for $10 \mathrm{~min}$. Absorptions at 510 and $700 \mathrm{~nm}$ of e supernatant in buffers at $\mathrm{pH} 1.0\left(A_{510} ., A_{710}\right)$ and $\mathrm{pH} 4.5\left(A_{510}^{*}, A_{710}^{*}\right)$ were measured in triplicate using a UV spectrophotometer, applying the equation $A=\left(A_{510}-A_{700}\right)-\left(A_{510}^{*}-A_{700}^{*}\right)$, with a molar extinction coefficient of cyanidin-3-glucoside (Cy-3-Glu) of 29,600 L/(mol-cm). Results were expressed as milligrams of equivalent $\mathrm{Cy}-3$-Glu per gram.

\subsection{Microscope Observation}

To observe the pigments distribution in the leaf tissues of leave, four types of leaves (the untreated leaf, the leaf under full light, $50 \%$ and $75 \%$ of full light for 75 days, respectively) were chosen for freehand cross sectioning. Middle parts of typical leaf samples from each treatment were sliced by two overlapping blades; a section from the gap between the blades were mounted in water, and then put onto a glass slide sealed with a cover glass. The sections were viewed immediately by a light microscope. In order to furtheobserve the histological changes, paraffin sections were conducted on the four types of leaves using the method of Liu et al. [37]. The green and red parts of middle parts were cut into small cubes. They were fixed with FAA solution, dehydrated by increasing concentrations of ethanol, made transparent in xylene, embedded in paraffin and sliced. Then, after being fixed on microslides and subjected to toluidine bule staining, the sections were sealed with resins and photographed at the microscope (Leica DM1000, Leica Microsystems, Ltd., Germany). 


\subsection{Statistical Analysis}

We conducted every analytical determination at least three times, and processed preliminary experimental data and tables in Microsoft Excel. SPSS 26.0 software (IBM Crop., Armonk, NY, USA) was used to analyze the data, and the correlations were performed using Duncan's single factor analysis of variance (ANOVA). Differences showed by the ANOVA were considered statistically significant at $p<$ 0.05. Different lowercase letters indicate significance differences among three treatments in the same day. All values are mean $\pm \mathrm{SE}$.

\section{Results and Discussion}

\subsection{Morphological Changes of the Leaves under Different Light Conditions}

Shading treatment had a significantly effect on leaf morphology of A. comosus var. bracteatus. The morphological changes of the leaves under different light conditions are shown in Fig. 2. Plants under $75 \%$ and $50 \%$ shade grew well throughout the experimental period while sunburn was observed in the leaves of plants under full light; the degree of leaf sunburn increased with time of exposure. The marginal parts of the chimeric leaves under $75 \%$ shade firstly lost the red color and became white (about 45 days), then turned to green. The marginal parts of leaves under both full light and $50 \%$ shade maintained the red color during the period. However, sunburn spots occurred on the leaves under full light during about 60 days. According to previous studies, light damage was caused by the interaction of excess light and high leaf temperatures and as a consequence plant growth was affected [38,39]. Indeed, shading usually reduces plant growth, but some plants, especially many evergreens, benefit from shading in the warm areas. For Euonymus japonica Hand. -Mazz. 'Aureo-marginata', plant growth was optimized with 50\% shading [40]. Shading increased the growth of Rhododendron $\times$ 'Pink Ruffles' [41].
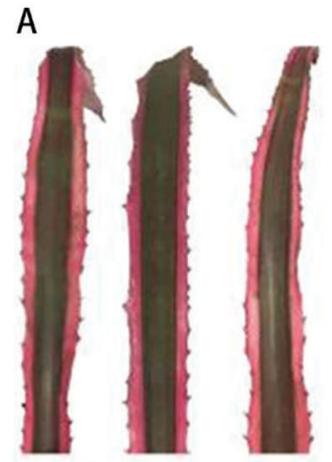

CK

$\mathrm{T} 1$

T2

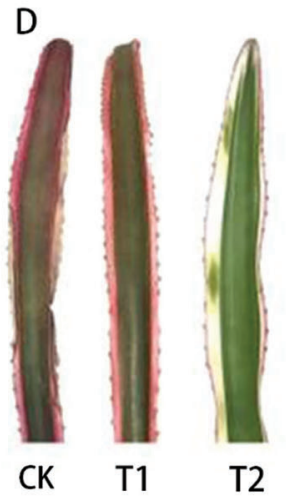

Figure 2: Visual foliage color changes of Ananas comosus var. bracteatus leaves under different light intensities. (CK) full light, (T1) 50\% shade, (T2) 75\% shade, (A) day 0, (B) day 15, (C) day 30, (D) day 45, (E) day 60, (F) day 75 
The color parameter and the color index of leaves varied among the experimental period (Tab. 1). For treatments $\mathrm{T} 1$ and $\mathrm{T} 2$, the redness $\left(\mathrm{a}^{*}\right)$ of the marginal part gradually decreased. The lightness $\left(\mathrm{L}^{*}\right)$ of the central part increased slightly as shade increased for all treatments indicating that the marginal part of leaves had a gradual transition from red to green, and the central parts of leaves became lighter for all treatments during our experiment. The redness $\left(a^{*}\right)$ and yellowness $\left(b^{*}\right)$ of marginal parts of leaves decreased faster than the central parts, which indicated that marginal parts had a greater anthocyanin degradation than the central part. The change in color can be quantified by the color index CI, which was reported to be related to the pigment composition in plant tissues $[42,43]$. Positive values indicate a yellow or red coloration, while negative values represent green color. In our study, it was observed that higher light intensity gave the leaves higher CI values with higher redness, which indicated that high irradiance stimulated the biosynthesis of anthocyanins, protecting against the damage due to excess light. Similar results have been found in Galax urceolata [9], where changes in pigments are related to light intensity. The higher redness $\left(\mathrm{a}^{*}\right)$ in the leaves under the three treatments enhanced the red leaf formation with higher color index because of the accumulation of anthocyanins in the tissues. Therefore, the chimeric leaves of the three treatments kept red in the first 30 days. However, with the increase in shading time, the CI values became lower and the leaf quickly lost its red color. This result showed that only few anthocyanins were in tissues, which was related to the anthocyanin degradation in leaves. After 75 days of $75 \%$ shading treatment, the leaf color of marginal parts changed from red to green with the decreased CI, which showed that shading influenced the leaf color of the marginal part apparently by decreasing the red color and increasing the green color [11]. Similar results were observed in the central part and the CI became negative, because more chlorophylls were present in the tissues of the central parts. From our results, light intensity had a great influence on the color parameters of $A$. comosus var. bracteatus leaves.

Table 1: Leaf color parameters ( $\left.\mathrm{L}^{*}, \mathrm{a}^{*}, \mathrm{~b}^{*}\right)$ and Color Index in the marginal and central parts of $A$. comosus var. bracteatus leaves exposed to different light intensities during the whole experiment. All values represent the mean $\pm \mathrm{SE}$, and the same letters indicate no significant differences in the three treatments $(p<0.05)$

\begin{tabular}{|c|c|c|c|c|c|}
\hline \multirow[t]{2}{*}{ Treatment time(d) } & \multirow[t]{2}{*}{ Treatment } & \multicolumn{4}{|c|}{ Marginal part } \\
\hline & & $\mathrm{L}^{*}$ & $a^{*}$ & $b^{*}$ & $\mathrm{CI}$ \\
\hline \multirow[t]{3}{*}{0} & $\mathrm{CK}$ & $53 \pm 2 \mathrm{a}$ & $43 \pm 3 a$ & $18 \pm 2 \mathrm{a}$ & $45.47 \pm 5.79 a$ \\
\hline & $\mathrm{T} 1$ & $51 \pm 4 \mathrm{a}$ & $43 \pm 2 a$ & $19 \pm 4 a$ & $44.97 \pm 7.24 \mathrm{a}$ \\
\hline & $\mathrm{T} 2$ & $52 \pm 5 \mathrm{a}$ & $46 \pm 4 a$ & $16 \pm 3 a$ & $59.96 \pm 19.63 a$ \\
\hline \multirow[t]{3}{*}{15} & CK & $52 \pm 3 a$ & $44 \pm 3 a$ & $16 \pm 5 a$ & $56.09 \pm 24.17 \mathrm{a}$ \\
\hline & $\mathrm{T} 1$ & $50 \pm 1 \mathrm{a}$ & $43 \pm 3 a$ & $20 \pm 2 a$ & $42.06 \pm 1.69 \mathrm{a}$ \\
\hline & $\mathrm{T} 2$ & $57 \pm 2 b$ & $39 \pm 2 a$ & $18 \pm 2 \mathrm{a}$ & $39.16 \pm 4.65 a$ \\
\hline \multirow[t]{3}{*}{30} & CK & $49 \pm 2 \mathrm{a}$ & $46 \pm 4 b$ & $18 \pm 3 \mathrm{a}$ & $53.73 \pm 11.21 \mathrm{a}$ \\
\hline & $\mathrm{T} 1$ & $51 \pm 2 \mathrm{a}$ & $45 \pm 4 b$ & $16 \pm 2 \mathrm{a}$ & $56.76 \pm 10.37 \mathrm{a}$ \\
\hline & $\mathrm{T} 2$ & $66 \pm 3 b$ & $26 \pm 2 \mathrm{a}$ & $20 \pm 3 a$ & $20.27 \pm 3.56 b$ \\
\hline \multirow[t]{3}{*}{45} & $\mathrm{CK}$ & $56 \pm 6 \mathrm{a}$ & $39 \pm 3 b$ & $17 \pm 3 \mathrm{a}$ & $41.08 \pm 5.77 \mathrm{a}$ \\
\hline & $\mathrm{T} 1$ & $59 \pm 3 a$ & $35 \pm 5 b$ & $17 \pm 1 \mathrm{a}$ & $34.37 \pm 4.16 \mathrm{a}$ \\
\hline & $\mathrm{T} 2$ & $74 \pm 8 b$ & $0 \pm 1 \mathrm{a}$ & $28 \pm 3 b$ & $-0.14 \pm 0.23 b$ \\
\hline
\end{tabular}




\begin{tabular}{|c|c|c|c|c|c|}
\hline \multirow[t]{2}{*}{ Treatment time(d) } & \multirow[t]{2}{*}{ Treatment } & \multicolumn{4}{|c|}{ Marginal part } \\
\hline & & $\mathrm{L}^{*}$ & $a^{*}$ & $b^{*}$ & $\mathrm{CI}$ \\
\hline \multirow[t]{3}{*}{60} & CK & $57 \pm 4 a$ & $33 \pm 3 c$ & $16 \pm 4 a$ & $36.68 \pm 8.61 \mathrm{a}$ \\
\hline & $\mathrm{T} 1$ & $57 \pm 6 a$ & $17 \pm 5 b$ & $20 \pm 2 a$ & $14.69 \pm 4.69 b$ \\
\hline & $\mathrm{T} 2$ & $59 \pm 1 \mathrm{a}$ & $-3 \pm 4 a$ & $31 \pm 3 b$ & $-1.74 \pm 1.78 c$ \\
\hline \multirow[t]{3}{*}{75} & CK & $56 \pm 5 b$ & $32 \pm 3 c$ & $18 \pm 2 \mathrm{a}$ & $32.40 \pm 5.82 \mathrm{a}$ \\
\hline & $\mathrm{T} 1$ & $57 \pm 1 b$ & $15 \pm 4 b$ & $21 \pm 1 \mathrm{a}$ & $12.41 \pm 2.97 b$ \\
\hline & $\mathrm{T} 2$ & $47 \pm 2 \mathrm{a}$ & $-1 \pm 3 \mathrm{a}$ & $26 \pm 2 b$ & $-1.24 \pm 2.39 c$ \\
\hline \multirow[t]{2}{*}{ Treatment time $(\mathrm{d})$} & Treatment & \multicolumn{4}{|c|}{ Central part } \\
\hline & & $\mathrm{L}^{*}$ & $a^{*}$ & $\mathrm{~b}^{*}$ & $\mathrm{CI}$ \\
\hline \multirow[t]{3}{*}{0} & $\mathrm{CK}$ & $28 \pm 1 \mathrm{a}$ & $6 \pm 2 \mathrm{ab}$ & $19 \pm 1 \mathrm{a}$ & $11.16 \pm 4.76 \mathrm{ab}$ \\
\hline & $\mathrm{T} 1$ & $27 \pm 2 \mathrm{a}$ & $4 \pm 2 \mathrm{a}$ & $17 \pm 1 \mathrm{ab}$ & $7.81 \pm 3.04 b$ \\
\hline & $\mathrm{T} 2$ & $27 \pm 2 \mathrm{a}$ & $7 \pm 1 b$ & $16 \pm 2 b$ & $17.40 \pm 3.30 \mathrm{a}$ \\
\hline \multirow[t]{3}{*}{15} & $\mathrm{CK}$ & $27 \pm 1 \mathrm{a}$ & $2 \pm 2 b$ & $16 \pm 2 \mathrm{a}$ & $3.77 \pm 3.51 \mathrm{a}$ \\
\hline & $\mathrm{T} 1$ & $26 \pm 3 a$ & $1 \pm 2 b$ & $17 \pm 2 \mathrm{a}$ & $2.12 \pm 3.87 \mathrm{a}$ \\
\hline & $\mathrm{T} 2$ & $27 \pm 2 \mathrm{a}$ & $-5 \pm 2 \mathrm{a}$ & $21 \pm 1 b$ & $-8.40 \pm 3.16 b$ \\
\hline \multirow[t]{3}{*}{30} & $\mathrm{CK}$ & $29 \pm 3 a$ & $0 \pm 1 \mathrm{a}$ & $18 \pm 2 \mathrm{a}$ & $-0.06 \pm 2.15 \mathrm{a}$ \\
\hline & $\mathrm{T} 1$ & $29 \pm 1 \mathrm{a}$ & $-1 \pm 1 \mathrm{a}$ & $21 \pm 3 a b$ & $-2.28 \pm 1.23 \mathrm{a}$ \\
\hline & $\mathrm{T} 2$ & $29 \pm 4 a$ & $-7 \pm 1 b$ & $23 \pm 1 b$ & $-11.11 \pm 1.84 b$ \\
\hline \multirow[t]{3}{*}{45} & $\mathrm{CK}$ & $30 \pm 3 a$ & $-3 \pm 2 c$ & $19 \pm 1 \mathrm{a}$ & $-6.11 \pm 3.12 \mathrm{a}$ \\
\hline & $\mathrm{T} 1$ & $29 \pm 2 \mathrm{a}$ & $-7 \pm 1 b$ & $20 \pm 2 \mathrm{ab}$ & $-11.96 \pm 1.53 \mathrm{ab}$ \\
\hline & $\mathrm{T} 2$ & $31 \pm 2 \mathrm{a}$ & $-11 \pm 2 \mathrm{a}$ & $23 \pm 2 b$ & $-15.90 \pm 4.88 b$ \\
\hline \multirow[t]{3}{*}{60} & $\mathrm{CK}$ & $33 \pm 3 a$ & $-4 \pm 1 c$ & $19 \pm 2 \mathrm{a}$ & $-7.19 \pm 1.88 \mathrm{a}$ \\
\hline & $\mathrm{T} 1$ & $28 \pm 2 \mathrm{a}$ & $-9 \pm 1 b$ & $19 \pm 2 \mathrm{a}$ & $-17.89 \pm 2.84 b$ \\
\hline & $\mathrm{T} 2$ & $32 \pm 4 a$ & $-15 \pm 2 \mathrm{a}$ & $25 \pm 1 b$ & $-18.19 \pm 3.59 b$ \\
\hline \multirow[t]{3}{*}{75} & $\mathrm{CK}$ & $30 \pm 1 \mathrm{a}$ & $-6 \pm 2 c$ & $19 \pm 2 \mathrm{a}$ & $-10.23 \pm 3.98 \mathrm{a}$ \\
\hline & $\mathrm{T} 1$ & $31 \pm 3 a$ & $-12 \pm 1 b$ & $19 \pm 1 \mathrm{a}$ & $-21.10 \pm 2.64 b$ \\
\hline & $\mathrm{T} 2$ & $29 \pm 4 a$ & $-17 \pm 3 a$ & $30 \pm 2 b$ & $-19.03 \pm 1.20 b$ \\
\hline
\end{tabular}

\subsection{Pigments Concentration Changes in Ananas comosus var. bracteatus Chimeric Leaves}

The leaf color is directly related to the pigments concentration of the leaves. In order to reveal the material basis of the leaf color changes, the pigment concentration of the marginal and central parts of chimeric leaves of $A$. comosus var. bracteatus were analyzed.

\subsubsection{Pigments Changes in the Center Green Part of the Chimeric Leaves}

Shading had significant influences on the accumulation of chlorophyll, carotenoid and anthocyanin in the green center parts of $A$. comosus var. bracteatus leaves (Figs. 3A-3C). The chlorophyll concentration in the central parts of chimeric leaves under full sunlight and $50 \%$ shading treatments kept decreasing 
during 75 days, and the chlorophyll concentration under full light treatment decreased faster than that under $50 \%$ shading. This finding may be related to the result of the interaction between long-term adaptions in plants and a greater degradation caused by high solar radiation. High light stress affects the photosynthetic apparatus and its functioning in a direct or indirect way. There exists short and long-term responses in plants to acclimate themselves to various light intensities. Plants can suffer from the inhibition of photosynthetic quantum conversion and electron transport under too high irradiance, which results in short-term declines in photosynthetic function [44]. Long-term high light stress, often accompanied by temperature and water stresses, leads to a decline in chlorophyll concentration [45]. Leaves also under go many changes such as the formation of sun-type chloroplasts with lower amounts of high-harvesting pigments, less LHC-II (LHCPs) and a higher capacity for photosynthetic quantum conversion, which helps plants to avoid damage or photoinhibition [46,47]. In addition, chlorophyll degradation often occurs in the process of plants acclimation to light stress. Light was reported to enhance the degradation of chlorophyll in Camellia sinensis L. cultivar 'Huangjinya' [48]. Furthermore, it was reported that prolonged exposure to high light intensities may be harmful to the photosynthetic apparatus [49]. Chlorophyll was usually synthesized and photo-oxidized in the presence of light, so the concentration of chlorophyll was greatly affected by shading [4,50]. Moreover, the degree of photosynthetic damage increased with the time of exposure to high solar radiation, and severe photoinhibition was followed by leaf death [40]. It is also important to point out that there was a remarkable increase in chlorophyll concentration under $75 \%$ shade for 45 days, which demonstrated the plant's ability to develop mechanisms for improving light harvesting [51]. The carotenoid concentration decreased apparently under full light and 50\% shading treatments during the 75 days. But under $75 \%$ shading it decreased during the first 45 days, and then increased apparently in the subsequent period (Fig. 3B). Increased carotenoids concentration under shading can enhance light absorption and transfer to chlorophyll for photosynthesis [52]. During the experiment time, anthocyanins concentration of the green center part of the leaves all decreased consequently. When the light intensity decreased, the concentration of anthocyanin decreased more. The highest anthocyanin concentration was observed under full light (Fig. 3C). Previous studies showed that anthocyanins have the ability to protect chlorophyll pigments from damage under high solar radiation conditions [53].

\subsubsection{Pigments Changes in the Red Margin Parts of the Chimeric Leaves}

During the treatment period, the chlorophyll concentrations of the red margin part of chimeric leaves increased in all three treatments. There were apparent differences in the increasing chlorophyll concentration among the three treatments. Under $75 \%$ shading, the chlorophyll concentration was the highest and increased the fastest, especially after 45 days of treatment (Fig. 3D). Along the treatment procedure, the carotenoid concentration of marginal parts of the leaves increased consequently under the three treatments. But there were no significant differences in carotenoid concentration among the three treatments (Fig. 3E). However, shading decreased the anthocyanin concentration in the red margin parts of the leaves (Fig. 3F). The concentration of anthocyanin decreased more when the shading intensity and time increased. At the first 30 days of full light and 50\% shading, the anthocyanin concentration increased, and then decreased quickly in the following period. Under $75 \%$ shading, the anthocyanin content decreased consequently along the 75 days. It has been shown that the light exposure was a prerequisite for significant anthocyanin synthesis, and a high level of solar radiation promoted the anthocyanin synthesis $[9,10]$. In addition, anthocyanin in epidermal tissues can provide some protection from UV solar radiation [54]. In order to maintain plant growth, chlorophyll gradually accumulated in the red part while the anthocyanin concentration decreased after day 30. 

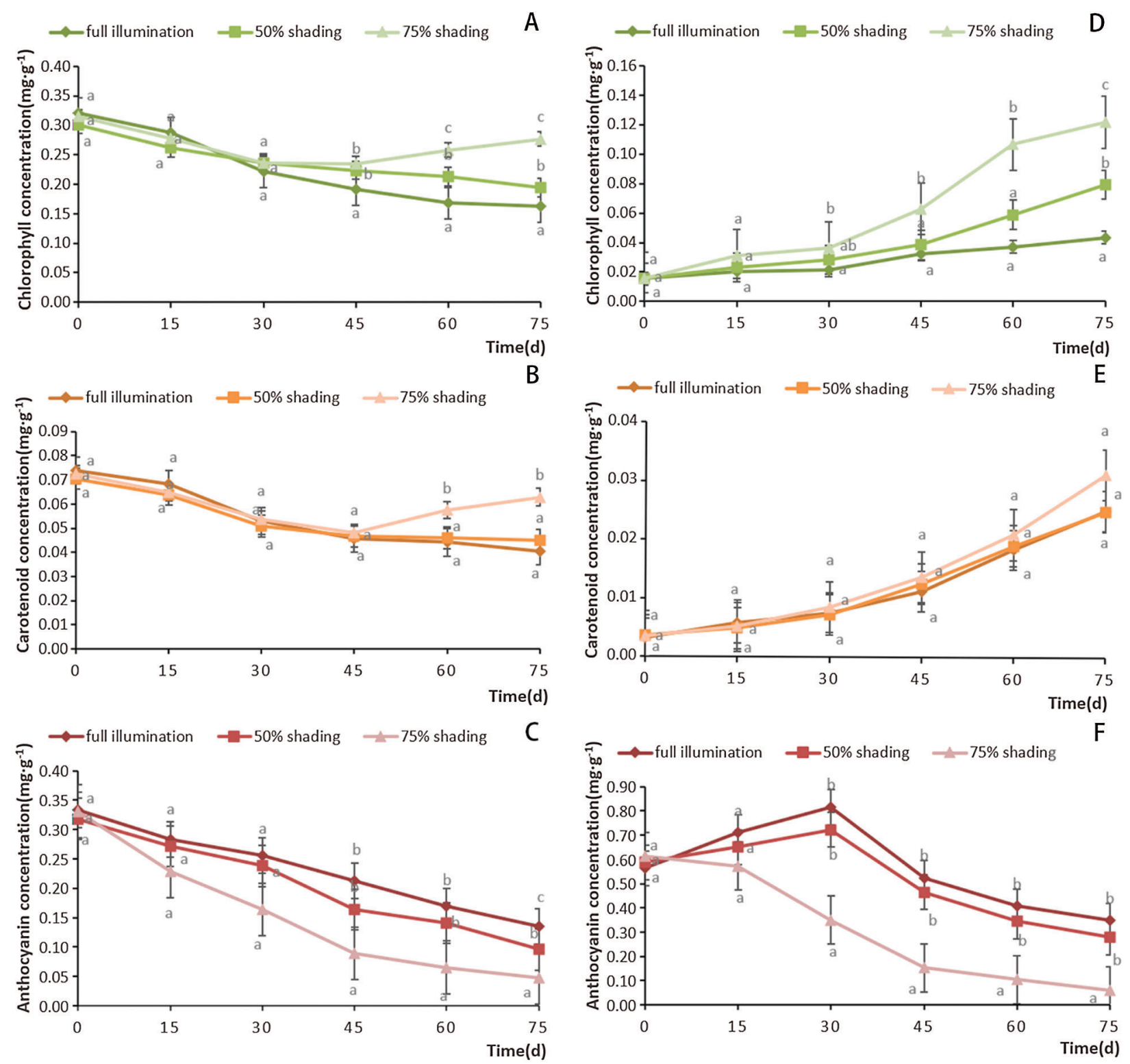

Figure 3: Changes of chlorophyll (A), carotenoid (B) and anthocyanin (C) concentrations in the central parts of Ananas comosus var. bracteatus leaves, and the changes of chlorophyll (D), carotenoid (E) and anthocyanin (F) concentrations in the marginal parts under different shading treatments. All values are means \pm SE. Different letters mark statistical differences among shade treatments in the same day $(p<0.05)$

\subsubsection{Proportion of Pigments in Ananas comosus var. bracteatus Chimeric Leaves}

The leaf color was determined by the concentration and relative proportion of the chlorophyll, carotenoid and anthocyanin concentrations (Fig. 4). In the green center parts of the chimeric leaves, chlorophyll and anthocyanin were the dominant pigments sharing about $45 \%$ of the total pigments, respectively, during the first 15 days, and the central parts of the leaves were dark green. This was the result of the interaction between the reflectance of green chlorophyll and red anthocyanin. From days 30 to 75 , the proportion of chlorophyll concentration increased apparently. The increase in the chlorophyll proportion was more apparent with the increase of shading intensity. After 75 days of $75 \%$ 
shading, the proportion of chlorophyll increased to about $70 \%$ and the proportion of anthocyanin decreased to about $10 \%$. The proportion of carotenoid increased slightly along the shading time and shading intensity (Fig. 4A). According to the increase of chlorophyll and decrease of anthocyanin, the color of the central parts of the chimeric leaves changed from dark green to green.
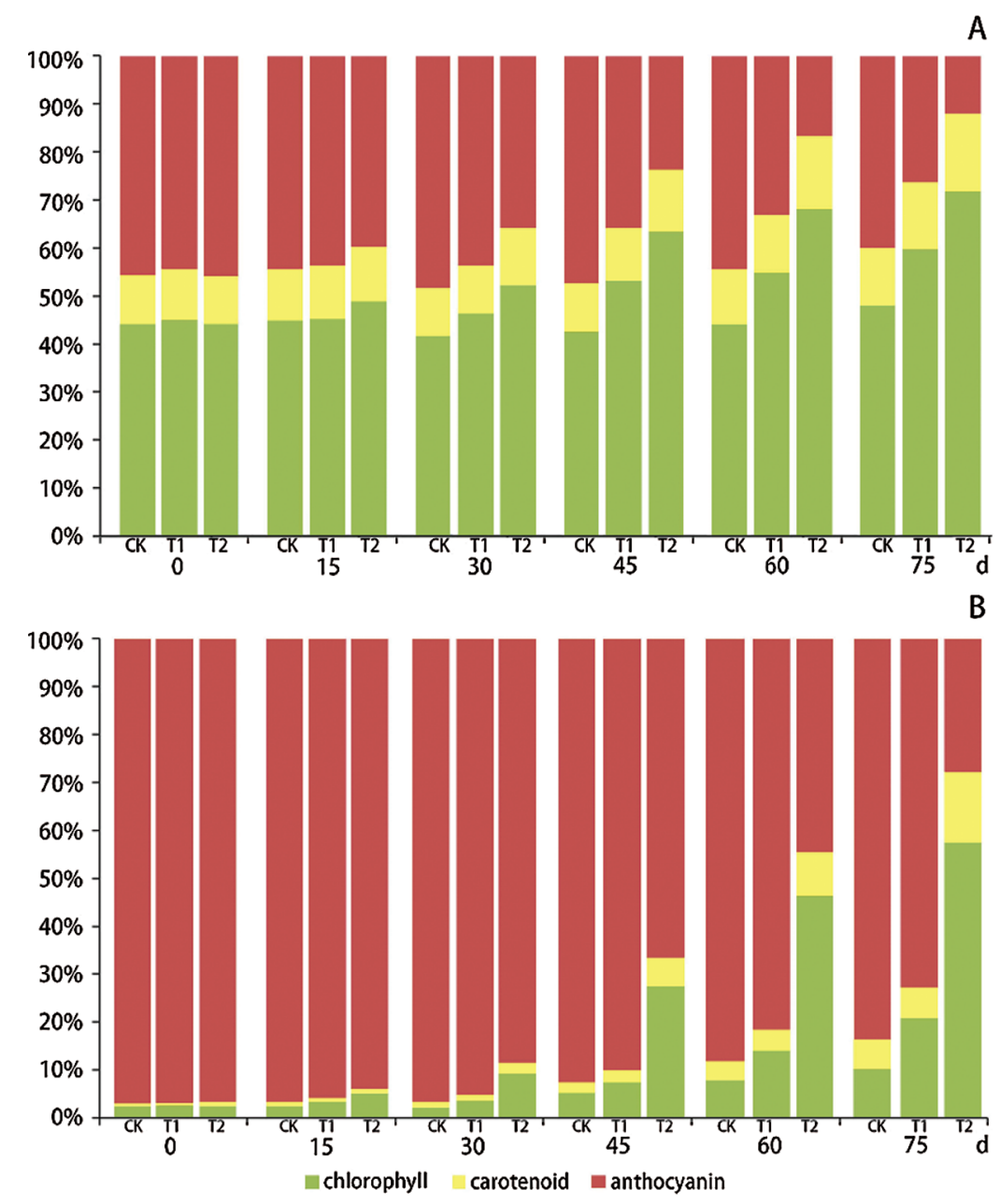

Figure 4: The changes of relative proportion of the chlorophyll, carotenoid and anthocyanin concentrations in the green center parts (A) and red margin parts (B) of Ananas comosus var. bracteatus chimeric leaves under different light intensities

In the red margin parts of the chimeric leaves, anthocyanin was the dominant pigment. At the first 30 days, anthocyanin accounted for more than $90 \%$ of the total pigment concentration. After 30 days of treatment, the proportion of chlorophyll and carotenoid increased and that of anthocyanin decreased (Fig. 4B). As the shading intensity and time increased, the chlorophyll proportion increased more, and the anthocyanin proportion decreased more. Under full light treatment for 75 days, the proportion of anthocyanin concentration remained more than $80 \%$ of the total pigments concentration, while under 75 days of $75 \%$ shading treatment the proportion of anthocyanin decreased to $28 \%$. Under $50 \%$ shading for 75 days, the anthocyanin proportion was more than $70 \%$. The changes in pigments relative proportions resulted in the morphology changes we observed. It is notable that the proportion of 
carotenoid in the red margin parts of the leaves increased more apparently than that in the green center parts of leaves, especially under $75 \%$ of shading treatment. There were different pigment ratios in plants grown under different light conditions, and the ratios of pigments could reflect the light adaptability of plants. Plants grown under high light tended to produce more anthocyanin, which enhanced the ornamental character of plants $[9,12,54]$. However, plants tended to produce more chlorophyll under low light condition to maintain sufficient photosynthetic antennas. This response allowed the plant to capture the required light energy $[8,10]$. In addition, the different colorations between the central and marginal parts of the chimeric leaves were the result of the different concentration and ratio between anthocyanin and chlorophyll. Shading can influence the pigment ratios in A. comosus var. bracteatus, which agrees with other studies $[10,12]$.

\subsection{Pigments Location and Leaf Structure Changes of Chimeric Leaves}

In order to reveal the distribution of pigments in the chimeric leaves and the effect of shading on the structure of the leaf tissues, anatomic observations of the leaves were carried out (Fig. 5). The red chimeric leaves used in this experiment consisted of the red and green tissues (Fig. 5A). In the red margin part, no chloroplast was observed in the mesophyll cells, and all the mesophyll cells were white (Figs. 5B1, 5C1, 5E1). In the green central part of the leaf, many chloroplasts were observed in the mesophyll cells, which gave this leaf part of its green color (Figs. 5B1, 5D1, 5F1). Red cells containing anthocyanin were located in the upper and lower epidermis of the cells and the 1-2 cell layer beneath the epidermis of the leaf (Figs. 5C1, 5D1). Anthocyanins were located in the vacuoles of the cells, which made the almost entire cells appear red. Under full light for 75 days, the red cells with anthocyanins always existed in/under the epidermis in both red margin and green center parts of the leaves, but were less than those in leaves at 0 day (Figs. 5A2, 5B2, 5C2, 5D2). Almost no green cells with chloroplasts were observed in the mesophyll cells of marginal part under full light (Figs. 5B2, 5C2). However, a few green spots were observed in the red margin of the leaf under $50 \%$ shading for 75 days (Fig. 5A3) because some green cells with chloroplasts existed in the red margins (Figs. 5B3, 5C3). Red cells of the leaf under $50 \%$ shading existed in/under the upper and lower epidermis of red margin and green center part of the leaf, but were lower than those of the leaf in the 0 day (Figs. 5B3, 5C3, 5D3). After treated with $75 \%$ shading for 75 day, the marginal parts of the leaf lost the red coloration and then turned green (Fig. 5A4). Red cells were seldom observed in/under the epidermis of the leaf. However, green cells with chloroplasts apparently accumulated in the marginal parts of the leaf (Figs. 5B4, 5C4, 5D4). It is also important to point out that there was no coexistence of chlorophyll and anthocyanin in a single cell.

Light intensity is an important factor for the regulation of the photosynthetic mechanism. However, plants absorb more light than they need to saturate photosynthesis and consequently a high light intensity may cause the damage of the photosynthetic machinery. With increasing time of exposure to high light conditions, the degree of damage will increase too and the leaf death can occur [39]. In our present study, full light was probably too much for A. comosus var. bracteatus. As is already known, light can promote structural changes in leaf tissues. The mesophyll cells in the marginal and central tissues of the leaves under full light were reduced in size, and some of them were wrinkled in transverse section (Figs. 5E2, 5F2). It could be that excessive light and high leaf temperature resulted in water loss from the cells. However, the mesophyll cells under $75 \%$ shading were oval and turgid (Figs. 5E4, 5F4). Under the cuticle endowed epidermis of the leaf central green part, large parenchyma cells have also a function for water storage, an important structural feature of A. comosus var. bracteatus as a drought-enduring plant adapted to drought environments. This is an important structural feature of the green center part of chimeric leaves. 

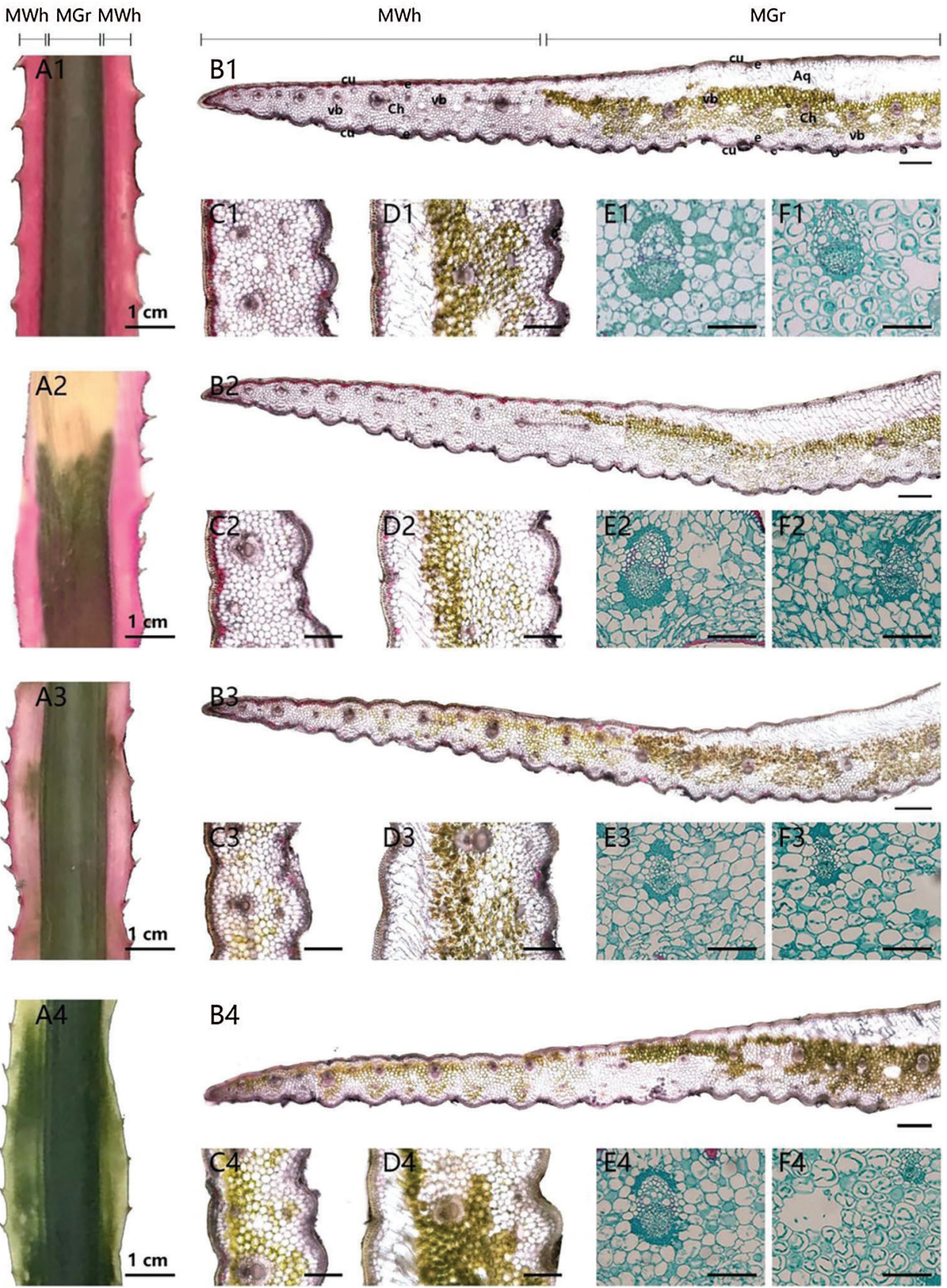

B4
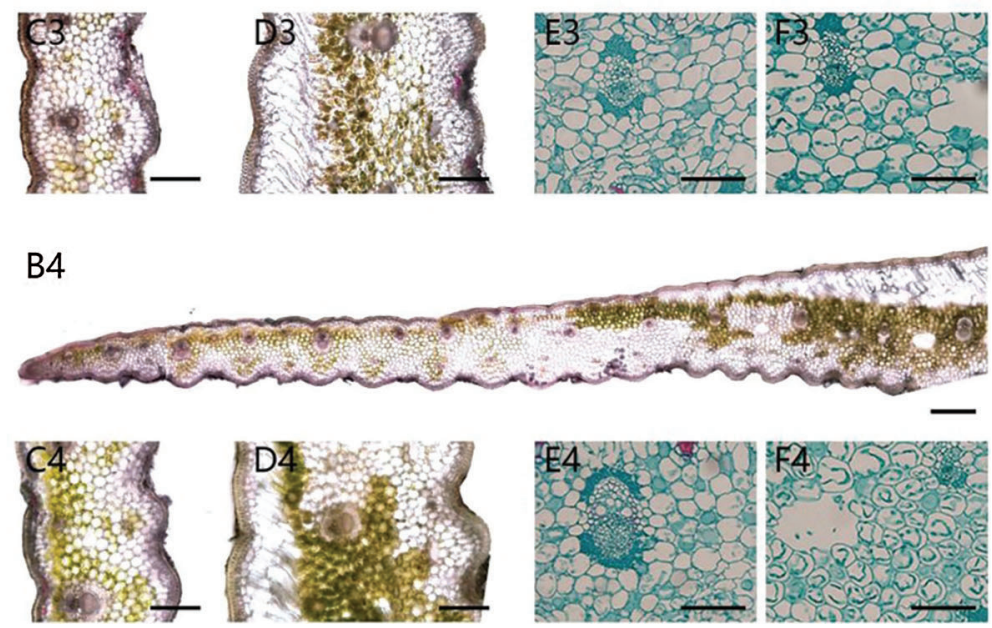

Figure 5: The pigments location and anatomic character of the central part and marginal parts of the chimeric leaves. (A1-F1) The anatomic structure of the leaf at 0 day. (A2-F2) The anatomic structure of the leaf under full light (CK) for 75 days (A3-F3) The anatomic structure of the leaf under $50 \%$ shading (T1) for 75 days. (A4-F4) The anatomic structure of the leaf under $75 \%$ shading (T2) for 75 days. (A) Leaf sample (Scale bars $=1 \mathrm{~cm}$ ). (B) Leaf cross-section (Scale bars $=400 \mu \mathrm{m}$ ). (C) The distribution of pigments in marginal tissues (Scale bars $=200 \mu \mathrm{m}$ ). (D) The distribution of pigments in the central tissues (Scale bars $=200 \mu \mathrm{m}$ ). (E) The mesophyll parenchyma cell in the marginal parts of the chimeric leaves (Scale bars $=100 \mu \mathrm{m}$ ). (F) The mesophyll parenchyma cell in the central part of the chimeric leaves (Scale bars $=100 \mu \mathrm{m}$ ). MWh, white tissue; Mgr, green tissue; $\mathrm{Cu}$, cuticle; e, epidermis; $\mathrm{Ch}$, mesophyll parenchyma; Aq, water storage parenchyma; vb, vascular bundle 


\section{Conclusions}

In this study, we showed that light intensity affects the leaf color; color parameters; pigment accumulation, distribution and ratio; mesophyll cells, and chloroplast occurrence in the marginal and central parts of chimeric leaves of A. comosus var. bracteatus. $75 \%$ shading boosted the decrease in anthocyanin concentration, the increase in chlorophyll concentration, and the number of chloroplasts in the mesophyll cells, and the leaves changed their color from red to green reducing their plant ornamental value. However, high irradiance promoted the accumulation of anthocyanins in the mesophyll cells, the relative proportion of anthocyanin concentration and, consequently, the redness $\left(\mathrm{a}^{*}\right)$ of the marginal parts of chimeric leaves. The plants exposed to full light and 50\% shade could maintain red and had a higher ornamental value. In addition, long exposure to full light contributed to light damage or even leaf death, the occurrence of wrinkled and smaller mesophyll cells in A. comosus var. bracteatus. Fifty percent shade could prevent the light damage caused by full light. In order to balance its growth and ornamental value, $50 \%$ shading is proposed as a good cultivation condition for A. comosus var. bracteatus in summer.

Acknowledgement: We are thankful to Sichuan Agricultural University, China, for providing support for the present investigation.

Funding Statement: This work was funded by the National Natural Science Foundation of China (Grant Nos. 31971704; 31770743).

Conflicts of Interest: The authors declare that they have no conflicts of interest to report regarding the present study.

\section{References}

1. Yang, Y. X., Chen, X. X., Xu, B., Li, Y. X., Ma, Y. H. et al. (2015). Phenotype and transcriptome analysis reveals chloroplast development and pigment biosynthesis together influenced the leaf color formation in mutants of anthurium andraeanum 'Sonate'. Frontiters in Plant Science, 6, 139. DOI 10.3389/fpls.2015.00139.

2. Wang, Y., Liu, S., Tian, X., Fu, Y., Jiang, X. et al. (2018). Influence of light intensity on chloroplast development and pigment accumulation in the wild-type and etiolated mutant plants of Anthurium andraeanum 'Sonate'. Plant Signaling \& Behavior, 13(8), e1482174. DOI 10.1080/15592324.2018.1482174.

3. Zhao, M. H., Li, X., Zhang, X. X., Zhang, H., Zhao, X. Y. (2020). Mutation mechanism of leaf color in plants: A review. Forests, 11(8), 1-19. DOI 10.3390/F11080851.

4. Dai, Y. J., Shen, Z. G., Liu, Y., Wang, L. L., Hannaway, D. et al. (2009). Effects of shade treatments on the photosynthetic capacity, chlorophyll fluorescence, and chlorophyll content of Tetrastigma hemsleyanum diels et gilg. Environmental and Exprimental Botany, 65, 177-182. DOI 10.1016/j.envexpbot.2008.12.008.

5. Fischer, R. A., Turner, N. C. (1978). Plant productivity in the arid and semiarid zones. Annual Review of Plant Physiology, 29, 277-317. DOI 10.1146/annurev.pp.29.060178.001425.

6. Surpin, M., Larkin, R. M., Chory, J. (2002). Signal transduction between the chloroplast and the nucleus. The Plant Cell, 14, 327-338. DOI 10.1105/tpc.010446.

7. Norcini, J. G., Andersen, P. C., Knox, G. W. (2019). Light intensity influences leaf physiology and plant growth characteristics of Photinia $\times$ fraseri. Journal of the American Society for Horticultural Science, 116(6), 10461051. DOI 10.21273/jashs.116.6.1046.

8. Kong, D. X., Li, Y. Q., Wang, M. L., Bai, M., Zou, R. et al. (2016). Effects of light intensity on leaf photosynthetic characteristics, chloroplast structure, and alkaloid content of Mahonia bodinieri (Gagnep.) laferr. Acta Physiologiae Plantarum, 38, 1-15. DOI 10.1007/s11738-016-2147-1.

9. Hughes, N. M., Neufeld, H. S., Burkey, K. O. (2005). Functional role of anthocyanins in high-light winter leaves of the evergreen herb Galax urceolata. New Phytologist, 168, 575-587. DOI 10.1111/j.1469-8137.2005.01546.x. 
10. Palaniswamy, U. R. (2005). Effect of light intensity on the pigment composition and oxalic acid concentrations in kalamegh (Andrographis paniculata) leaf. Acta Horticulture, 680, 109-114. DOI 10.17660/ ActaHortic.2005.680.15.

11. Brand, M. H. (1997). Shade influences plant growth, leaf color, and chlorophyll content of Kalmia latifolia L. cultivars. HortScience, 32(2), 206-208. DOI 10.21273/hortsci.32.2.206.

12. Nguyen, P., Cin, V. D. (2009). The role of light on foliage colour development in coleus (Solenostemon scutellarioides (L.) codd). Plant Physiology and Biochemistry, 47(10), 934-945. DOI 10.1016/j. plaphy.2009.06.006.

13. Shi, M. Z., Xie, D. Y. (2010). Features of anthocyanin biosynthesis in pap1-d and wild-type Arabidopsis thaliana plants grown in different light intensity and culture media conditions. Planta, 231, 1385-1400. DOI 10.1007/ s00425-010-1142-9.

14. Hara, M., Oki, K., Hoshino, K., Kuboi, T. (2003). Enhancement of anthocyanin biosynthesis by sugar in radish (Raphanus sativus) hypocotyl. Plant Science, 164, 259-265. DOI 10.1016/S0168-9452(02)00408-9.

15. Zheng, Y. J., Tian, L., Liu, H. T., Pan, Q. H., Zhan, J. C. et al. (2009). Sugars induce anthocyanin accumulation and flavanone 3-hydroxylase expression in grape berries. Plant Growth Regulation, 58, 251-260. DOI 10.1007/ s10725-009-9373-0.

16. Tanaka, Y., Sasaki, N., Ohmiya, A. (2008). Biosynthesis of plant pigments: Anthocyanins, betalains and carotenoids. The Plant Journal, 54, 733-749. DOI 10.1111/j.1365-313X.2008.03447.x.

17. Holton, T. A., Cornish, E. C. (1995). Genetics and biochemistry of anthocyanin biosynthesis. The Plant Cell, 7 , 1071-1083, DOI 10.1016/c2009-0-26069-7.

18. Passeri, V., Koes, R., Quattrocchio, F. M. (2016). New challenges for the design of high value plant products: Stabilization of anthocyanins in plant vacuoles. Frontiers in Plant Science, 7, 153, DOI 10.3389/fpls.2016.00153.

19. Wu, J. W., Li, J. Y., Su, Y., He, Q., Wang, J. H. et al. (2017). A morphophysiological analysis of the effects of drought and shade on Catalpa bungei plantlets. Acta Physiologiae Plantarum, 39, 80. DOI 10.1007/s11738017-2380-2.

20. Trojak, M., Skowron, E. (2017). Role of anthocyanins in high-light stress response. World Scientific News, 81(2), 150-168. www.worldscientificnews.com.

21. Coste, S., Roggy, J. C., Imbert, P., Born, C., Bonal, D. et al. (2005). Leaf photosynthetic traits of 14 tropical rain forest species in relation to leaf nitrogen concentration and shade tolerance. Tree Physiology, 25, 1127-1137. DOI 10.1093/treephys/25.9.1127.

22. Valladares, F., Niinemets, Ü. (2008). Shade tolerance, a key plant feature of complex nature and consequences. Annual Review of Ecology Evolution and Systematics, 39, 237-257. DOI 10.1146/annurev. ecolsys.39.110707.173506.

23. Xue, Y. B., Ma, J., He, Y. H., Yu, S., Lin, Z. et al. (2019). Comparative transcriptomic and proteomic analyses of the green and white parts of chimeric leaves in Ananas comosus var. bracteatus. Peer J, 10(7), e7261. DOI 10.7717/peerj.7261.

24. Mao, M. Q., Xue, Y. B., He, Y. H., Zhou, X. Z. X., Rafique, F. et al. (2020). Systematic identification and comparative analysis of lysine succinylation between the green and white parts of chimeric leaves of Ananas comosus var. bracteatus. BMC Genomics, 21, 1-15. DOI 10.1186/s12864-020-6750-6.

25. Ma, J., Kanakala, S., He, Y. H., Zhang, J. L., Zhong, X. L. (2015). Transcriptome sequence analysis of an ornamental plant, Ananas comosus var. bracteatus, revealed the potential unigenes involved in terpenoid and phenylpropanoid biosynthesis. PLoS One, 10(3), e0119153DOI 10.1371/journal.pone.0119153.

26. Li, X., Kanakala, S., He, Y. H., Zhong, X. L., Yu, S. M. et al. (2017). Physiological characterization and comparative transcriptome analysis of white and green leaves of Ananas comosus var. bracteatus. PLOS One, 12(1), e0169838. DOI 10.1371/journal.pone.0169838.

27. Xiong, Y. Y., Ma, J., He, Y. H., Lin, Z., Li, X. et al. (2018). High-throughput sequencing analysis revealed the regulation patterns of small RNAs on the development of A. comosus var. bracteatus leaves. Scientific Reports, 8(1), 1-11. DOI 10.1038/s41598-018-20261-z. 
28. Lin, Z., Xiong, Y. Y., Xue, Y. B., Mao, M. Q., Xiang, Y. X. et al. (2019). Screening and characterization of long noncoding RNAs involved in the albinism of Ananas comosus var. bracteatus leaves. PLoS One, 14(11), e0225602. DOI 10.1371/journal.pone.0225602.

29. Zhou, X. Z. X., Xue, Y. B., Mao, M. Q., He, Y. H., Adjei, M. O. et al. (2021). Metabolome and transcriptome profiling reveals anthocyanin contents and anthocyanin-related genes of chimeric leaves in ananas comosus var. Bracteatus, 22, 331. DOI 10.1186/s12864-021-07642-x.

30. Ren, J., Liu, Z. Y., Chen, W. S., Xu, H. Z., Feng, H. (2019). Anthocyanin degrading and chlorophyll accumulation lead to the formation of bicolor leaf in ornamental kale. International Journal of Molecular Sciences, 20(3), 603. DOI 10.3390/ijms20030603.

31. Bae, C. H., Abe, T., Nagata, N., Fukunishi, N., Matsuyama, T. et al. (2000). Characterization of a periclinal chimera variegated tobacco (Nicotiana tabacum L.). Plant Science, 151, 93-101. DOI 10.1016/S0168-9452(99) 00205-8.

32. Wang, N., Zhu, T. Q., Lu, N., Wang, Z., Yang, G. J. et al. (2019). Quantitative phosphoproteomic and physiological analyses provide insights into the formation of the variegated leaf in Catalpa fargesii. Internatial Journal of Molecular Sciences, 20(8), 1895. DOI 10.3390/ijms20081895.

33. Marcotrigiano, M. (2001). Genetic mosaics and the analysis of leaf development. International Journal of Plant Sciences, 162(3), 513-525. DOI 10.1086/320138.

34. Voss, D. H. (1992). Relating colorimeter measurement of plant color to the royal-horticultural-society color chart. Hortscience, 27(12), 1256-1260. DOI 10.21273/HORTSCI.27.12.1256.

35. Pinto-Acero, Y. L., Alvarado-Gaona, A. E., Burgos-Ávila, Y. E., Balaguera-López, H. E., Ramirez gonzalez, S. L. (2019). Characterization of three Arracacia xanthorrhiza bancroft genotypes using morphological and color parameters. Revista Colombiana de Ciencias Hortícolas, 13(3), 426-434. DOI 10.17584/rcch.2019vl3i3.8948.

36. Gao, J. F. (2006). Experimental guidance of plant physiology, pp. 74-76. China: Beijing Higher Education Press.

37. Liu, X. X., Pan, Y. P., Liu, C., Ding, Y. Y., Wang, X. et al. (2020). Cucumber fruit size and shape variations explored from the aspects of morphology, histology, and endogenous hormones. Plants, 9, 772. DOI 10.3390/ plants9060772.

38. Kull, O. (2002). Acclimation of photosynthesis in canopies: Models and limitations. Oecologia, 133, 267-279. DOI 10.1007/s00442-002-1042-1.

39. Ludlow, M. M., Björkman, O. (1984). Paraheliotropic leaf movement in siratro as a protective mechanism against drought-induced damage to primary photosynthetic reactions: Damage by excessive light and heat. Planta, 161(6), 505-518. DOI 10.1007/BF00407082.

40. Newman, S. E., Follett, M. W. (1988). Irrigation frequency and shading influences on water relations and growth of container-grown Euonymus japonica 'Aureo-marginata'. Journal of Environmental Horticulture, 6(3), 96-100. DOI 10.24266/0738-2898-6.3.96.

41. Andersen, P. C., Norcini, J. G., Knox, G. W. (2019). Influence of irradiance on leaf physiology and plant growth characteristics of Rhododendron $\times$ 'Pink ruffles'. Journal of the American Society Horticultural Science, 116(5), 881-887. DOI 10.21273/jashs.116.5.881.

42. Mendoza, F. A., Dejmek, P., Aguilera, J. M. (2006). Calibrated color measurements of agricultural foods using image analysis. Postharvest Biology and Technology, 41(3), 285-295. DOI 10.1016/j.postharvbio.2006.04.004.

43. Balaguera-López, H. E., Espinal-Ruiz, M., Zacarías, L., Herrera, A. O. (2016). Effect of ethylene and 1methylcyclopropene on the postharvest behavior of cape gooseberry fruits (Physalis peruviana L.). Food Science and Technology International, 23(1), 86-96. DOI 10.1177/1082013216658581.

44. Krause, G. H. (1991). Chlorophyll fluorescence and photosynthesis: The basics. Annual Review of Plant Physiology, 42(1), 313-349. DOI 10.1146/annurev.pp.42.060191.001525.

45. Lichtenthaler, H. K., Burkart, S., Schindler, C., Stober, F. (1991). Changes in photosynthetic pigments and in vivo chlorophyll fluorescence parameters under photoinhibitory growth conditions. International Symposium, vol. 27, no. 3, pp. 343-353. Ceské Budejovice, Germany.

46. Lichtenthaler, H. K., (1981). Adaptation of leaves and chloroplasts to high quanta fluence rates. In: G. Akoyunoglou Photosynthesis. VI. Ed. pp. 273-287. Balaban Internat. Science Service, Philadelphia, USA. 
47. Mathur, S., Jain, L., Jajoo, A. (2018). Photosynthetic efficiency in sun and shade plants. Photosynthetica, 56, 354365. DOI 10.1007/s11099-018-0767-y.

48. Fan, Y. G., Zhao, X. X., Wang, H. Y., Tian, Y. Y., Xiang, Q. Z. et al. (2019). Effects of light intensity on metabolism of light-harvesting pigment and photosynthetic system in Camellia sinensis L. cultivar 'Huangjinya'. Environmental and Experimental Botany, 166(10), 103796. DOI 10.1016/j.envexpbot.2019.06.009.

49. Ramalho, J. C., Pons, T. L., Groeneveld, H. W., Azinheira, H. G., Nunes, M. A. (2000). Photosynthetic acclimation to high light conditions in mature leaves of Coffea arabica L.: Role of xanthophylls, quenching mechanisms and nitrogen nutrition. Australian Journal Plant Physiology, 27(1), 43-51. DOI 10.1071/pp99013.

50. de Carvalho Gonçalves, J. F., de Sousa Barreto, D. C., Dos Santos, U. M., Fernandes, A. V., Barbosa Sampaio, P. D. T. et al. (2005). Growth, photosynthesis and stress indicators in young rosewood plants (Aniba rosaeodora ducke) under different light intensities. Brazilian Journal of Plant Physiology, 17(3), 325-334. DOI 10.1590/s1677-04202005000300007.

51. Lei, T. T., Tabuchi, R., Kitao, M., Koike, T. (1996). Functional relationship between chlorophyll content and leaf reflectance, and light-capturing efficiency of Japanese forest species. Physiologia Plantarum, 96, 411-418. DOI 10.1111/j.1399-3054.1996.tb00452.x.

52. Czeczuga, B. (1987). Carotenoid contents in leaves grown under various light intensities. Biochemical Systematics and Ecology, 15(5), 523-528. DOI 10.1016/0305-1978(87)90098-6.

53. Steyn, W. J., Wand, S. J. E., Holcroft, D. M., Jacobs, G. (2002). Anthocyanins in vegetative tissues: A proposed unified function in photoprotection. New Phytologist, 155(3), 349-361. DOI 10.1046/j.1469-8137.2002.00482.x.

54. Burger, J., Edwards, G. E. (1996). Photosynthetic efficiency, and photodamage by UV and visible radiation, in red versus green leaf coleus varieties. Plant and Cell Physiology, 37(3), 395-399. DOI 10.1093/oxfordjournals.pcp. a028959. 